\title{
As Good As Water: Carry Forward the Spirit of Traditional Chinese Culture in China's Visual Communication
}

\author{
Yuyao Liu \\ Academy of Fine Arts, Liaoning Normal University, Dalian 116021, China \\ Yuyao109@163.com
}

Keywords: China, Visual communication, Carry forward, Traditional Chinese culture

\begin{abstract}
With the continuous development of the visual communication arts in all countries nowadays, mutual penetration has become a trend. In China, the development of visual communication design is leaps and bounds. However, in the state of rapid development, its aesthetic and values of contents have exposed a lot of problems. Therefore, under the environment of strongly advocating and promoting traditional Chinese culture, China's visual communication design should act as a pioneer to carry forward the fine traditional Chinese culture to purify the social atmosphere, so that the spirit of traditional Chinese culture can go to the world.
\end{abstract}

\section{Introduction}

Visual communication design is a design that uses visual symbols to convey a variety of information. Designers are sender of the message, and the communicated object is the recipient of the information. With people's continuous requirement of the development of the times, visual communication design has constantly been in innovation and development in terms of performance practices or technologies. In particular, the development of technology has become an important factor in promoting visual communication, for its development can even change the way in the exchange and dissemination of information in people's lives, and visual communication is a design discipline, it is very rich in content with a super-fast pace of development. At the same time, a lot of problems have cropped, namely, the aesthetic and fun guiding in its design content. Therefore, to carry forward the spirit of traditional Chinese culture in China's visual communication is essential in this era.

Traditional Chinese culture is people-oriented, emphasizing the "benevolence, righteousness, propriety, wisdom, faith", everything is started from the perspective of good to make the conflict in harmony and give a positive and upward force. When the positive culture is established, the low and vulgar values or aesthetic guiding will naturally die. From the audience of visual communication design, the audience has been affected by global culture.

\section{Learn visual communication}

The phrase "Visual Communication Design" is popular in the World Design Congress held in Tokyo, Japan, in 1960, and its contents are extensive and diverse. Its main contents include: poster newspapers, magazines and other printed promotional material posters as well as TV, electronic billboards, movies and other media.

Visual communication contains two basic concepts of "visual symbols" and "communication”. Popularly speaking, it is to use the "look" for visual expression and dissemination. Whatever the geography, age, language, etc., through visual media, people can conduct various communication and exchange of information. Visual communication can pass across the obstacles of each other's language and text.

\section{Development and status of visual communication}

From the point of view in general development of visual communication, it is basically risen in the mid-19th century in the printing extension of the arts technique design in Europe and the United 
States. With the continuous development of technology, visual communication design has also undergone a revolutionary development and leap.

In terms of China, after the reform and opening up to now, China's design education is also showing the explosive development. Whether it is university, college, or personal design courses class, they are constantly enrolling students of design class, resulting in constantly increment of visual communication talents.

With China's continuous development and the strengthening of foreign economic and cultural exchanges, Chinese design has also began to be prominent in the world. For example, in the major international design competition categories, the number of winners in China continues to increase, and a nascent Chinese forces should not be underestimated. Contemporary Chinese visual communication design is searching for the best show of its own way, and gradually completes a new round of transformation. Visual communication design has begun to shift from the plane of the previous morphological, static to a dynamic, integrated direction. The spread dissemination of visual communication design has been transformed from the static to static and dynamic combination, from the two-dimensional or three-dimensional space to go beyond four-dimensional space, leap from one-way communication to interactive communication. This makes the form of visual communication design increasingly diverse, with continuous innovation, it will promote the development of China's visual communication design.

\section{The rapid development chaos of visual communication}

Behind the rapid development of visual communication design, a lot of problems has grown, such as the non-standard of content spread, contents without the bottom line and the disrespect to humanities, history or religion and other issues.

The support of rapid development of technology for visual communication techniques and manifestations can not make up for the empty part of the contents of their works and ideas, while the number of personnel engaged in visual communication design is becoming more and more which is difficult to get all the comprehensive quality assurance, so the works inevitably pass off fish eyes for pearls.

Impact resulting from chaos. The range of visual communication is very wide and its spread range is also very wide and fast, so the impact of information it conveys is extensive and the spread velocity is fast, which has great impact on the social climate in large part.

For example, in today's society, each city will have outdoor advertising, which is that everyone living in the city can come into contact. Once the content of advertisements involves violence, pornography and other vulgar content, even if the performance way is very subtle, in monasteries it still has a very bad effect on people, and even bring very bad consequences. If the children in imitation see, it will have a very bad influence on the development of body and mind in them. When they grow up, they naturally think it is normal, because these vulgar content can be openly disclosed and public in the city, so that society ethos naturally falls. What is more, they will imitate, giving adverse consequences to themselves and their families as well as the society.

There are some other works giving misunderstanding and disrespect to culture, history and religious. Most obviously, historical figures and religious saint are used to take entertainment. For example, in order to achieve their own propaganda purposes, some of the pages processed the Christian image of God and Buddha Buddhist for secular and entertainment and misinterpret their image, which is disrespect for the culture and religion. And numbers believing in these two religions is very numerous in the world, the issues will be bound to cause their resentment, and even conflict, which is also a profound disrespect in terms of religious believers. For people without faith, once religious culture is misinterpreted, their religion will cause errors. The religious culture is an important part of world culture, once conflict is caused because of misunderstanding, the consequences are incalculable.

Establish the correct code of ethics. Nowadays, only a correct moral values can solve this chaos in order to reverse the situation fundamentally. 
Now some medium inspire people's welfare and moral psychology in the form of public service advertising. The most obvious is the growing number of public service advertising contest. For example, many municipalities begin to organize competitions of city-level public service ads, and the number of city is becoming more and more.

As for ethics, in fact, the best way is the fine moral spirit of traditional Chinese culture. Moral spirit of traditional Chinese culture is not only historic, but also experiences the millennium verification, and it can still inherit up to now, which is sufficient to explain the tenacious vitality.

As good as water__ traditional Chinese virtues. "As good as water" comes from Chapter VIII in the ancient Chinese classic “Tao Te Ching”. It's original: as good as water. Water benefits all things without struggle, at all of the evil, and so few on the road. Home of good land, good heart deep, with good kernel, articulate faith, good governance, good energy, moving good thing. Husband does not contend, so there's no blue. The general effect is that: the ultimate goodness between heaven and earth can be described by water. Water has nature of moisturizing and unchanging all things, and no conflict of interest with all things. Water has a broad mind, can local in the places people hate. The mind is quiet as an abyss, mercy and benevolence in the matter to the line, the jumping and trustworthy. There is no competition with them, so there is no mistakes.

Chinese traditional culture is profound, as good as water is one of the traditional Chinese spirit, which is also needed in today and to carry forward. "As good as water" is the oriental culture, but also peculiar methods and manners in traditional Chinese culture, that is to say, no play, unfortunately debate. When this quality is applied to visual communication design, not only will it pour into a new creative source, but also will have a positive impact on social climate.

At the same time, water also represents purity. For it is pure and clean, naturally there is no conflict in the culture, and it would not adversely affect the community, also inherit the spirit of traditional Chinese culture.

Let the spirit of traditional Chinese culture go to the world. As China continues to develop and the communication with the world continues to deepen, mutual penetration in design has become a trend. If China's visual communication design inherits and carries forward the spirit of traditional Chinese culture, I believe it will gradually cause the attention of the international community, and come to realize the spirit of traditional Chinese culture in China.

\section{References}

[1] Spring and Autumn, Li Dan, Xu Ling, Tao Te Ching (second version). Xi'an: Sanqin Press, 2012, 0438.

[2] X.J. Cheng. Wisdom of Tao Te Ching. Beijing: China Drama Press, 2006, 1: 38-39

[3] Goldstein J. BEIJING OPERA COSTUMES: The Visual Communication of Character and Culture. Pacific Affairs, 2009, 26(1):174-176.

[4] C. Liu, F. Wang, et al. Robust $\mathrm{H} \infty$ Control for Satellite Attitude Control System with Uncertainties and Additive Perturbation. International Journal of Science, 2014, 1(2): 1-9.

[5] S. Ding, R.A. Saunders. Talking up China: An analysis of China's rising cultural power and global promotion of the Chinese language. East Asia, 2006, 23(2): 3-33.

[6] S. Ding, R.A. Saunders. Talking up China: An analysis of China's rising cultural power and global promotion of the Chinese language. East Asia, 2006, 23(2): 3-33.

[7] Y. Su. Current Situation and Development Trend of Contemporary Chinese Visual Communication Design. Journal of Southwest Agricultural University(Social Science Edition), 2010, 8(1): 108-109. 